\title{
Correlation among Hydraulic Parameters of Moving Hydraulic Jump in Rectangular Open Channels
}

\author{
M.C.M. Nasvi, Z.A.M. Asmeer, F.M. Mowsoom and K.P.P. Pathirana
}

\begin{abstract}
The moving hydraulic jump is a phenomenon, which is often observed in field conditions. Since the parameters of moving hydraulic jump vary with time, analytical equations cannot be used to derive relationships among hydraulic jump parameters. Experimental investigations were carried out to study the relationships among hydraulic parameters of a moving hydraulic jump in a rectangular flume. The flow parameters were recorded for the moving hydraulic jump produced for different sluice gate opening sizes. Based on the recorded data, flows parameters such as specific energy, flow rate and pressure force at downstream of the hydraulic jump were calculated. Also, using momentum and energy equations time independent relationships were obtained. The relationship among moving hydraulic jump parameters were obtained in non dimensional form. The correlations between stationary and moving hydraulic jump parameters such as specific energy, flow rate, pressure force and flow depth were derived.
\end{abstract}

Keywords: Specific Energy, hydraulic jump, bed friction, supercritical, sub critical

\section{Introduction}

Hydraulic jump is a phenomenon that occurs when the flow changes suddenly from supercritical to slow moving sub critical state. Experimental evidence suggests that flow changes from supercritical to sub critical state can occur very abruptly through a hydraulic jump. Sufficient theoretical aspects and equations are available for describing stationary state hydraulic jumps where jump parameters do not change with time. Often hydraulic jumps occur in field condition are not stationary. Due to various hydraulic structures such as control gates, weirs, sluice gates and culverts moving hydraulic jumps can be seen during their normal operation. The hydraulic parameters of the jump vary with the time. Also incident of moving jump occurs in events where obstructing structures are placed along the channel due to the unsteady flow conditions. These occurrences suggest the importance of the further studies to obtain sufficient knowledge on moving hydraulic jump. An analytical approach to study the hydraulic behaviour of the moving hydraulic jump has not been successful. Therefore any studies related to moving hydraulic jumps need to be studied based on laboratory experiments followed by data analysis. This paper presents a laboratory study conducted to investigate the correlation among hydraulic parameters of moving hydraulic jump in a rectangular flume. Even though most of the channels in the real practise are trapezoidal in shape, a rectangular flume was used for the simplicity of analysis and considering the laboratory facilities.

\subsection{Experimental Procedure}

The flume having a rectangular cross section with width $0.3 \mathrm{~m}$, depth $0.3 \mathrm{~m}$ and length $12 \mathrm{~m}$ was used for the experiment. A constant head tank was used to supply the water continuously through a recirculation path. The experimental setup is shown in Figure 1.

The study was conducted in two stages; the first stage of the experiment was dealt with the stationary hydraulic jumps and the second stage with moving hydraulic jumps. A sluice gate positioned at the head of the channel and a tail gate were used to generate hydraulic jumps in the channel. A rectangular grid was fixed on the glass side wall of the channel in order to measure the distances along the channel and corresponding water levels during the experiments.

M.C.M. Nasvi, B.Sc. Eng. (Hons.)(Peradeniya), Department of Civil Engineering, University of Peradeniya, Sri Lanka.

Z.A.M. Asmeer, B.Sc. Eng. (Hons.)(Peradeniya), Department of Civil Engineering, University of Peradeniya, Sri Lanka.

M.F. Mowsoom. B.Sc. Eng. (Hons.)(Peradeniya), Department of Civil Engineering, University of Peradeniya, Sri Lanka.

Eng.(Prof.) K.P.P. Pathirana, B.Sc. Eng. (Hons.)(Peradeniya), M.Eng., Ph.D(KULeuven)., C.Eng., FIE(Sri Lanka), MICE(London), Professor of Civil Engineering, Department of Civil Engineering, University of Peradeniya, Sri Lanka. 


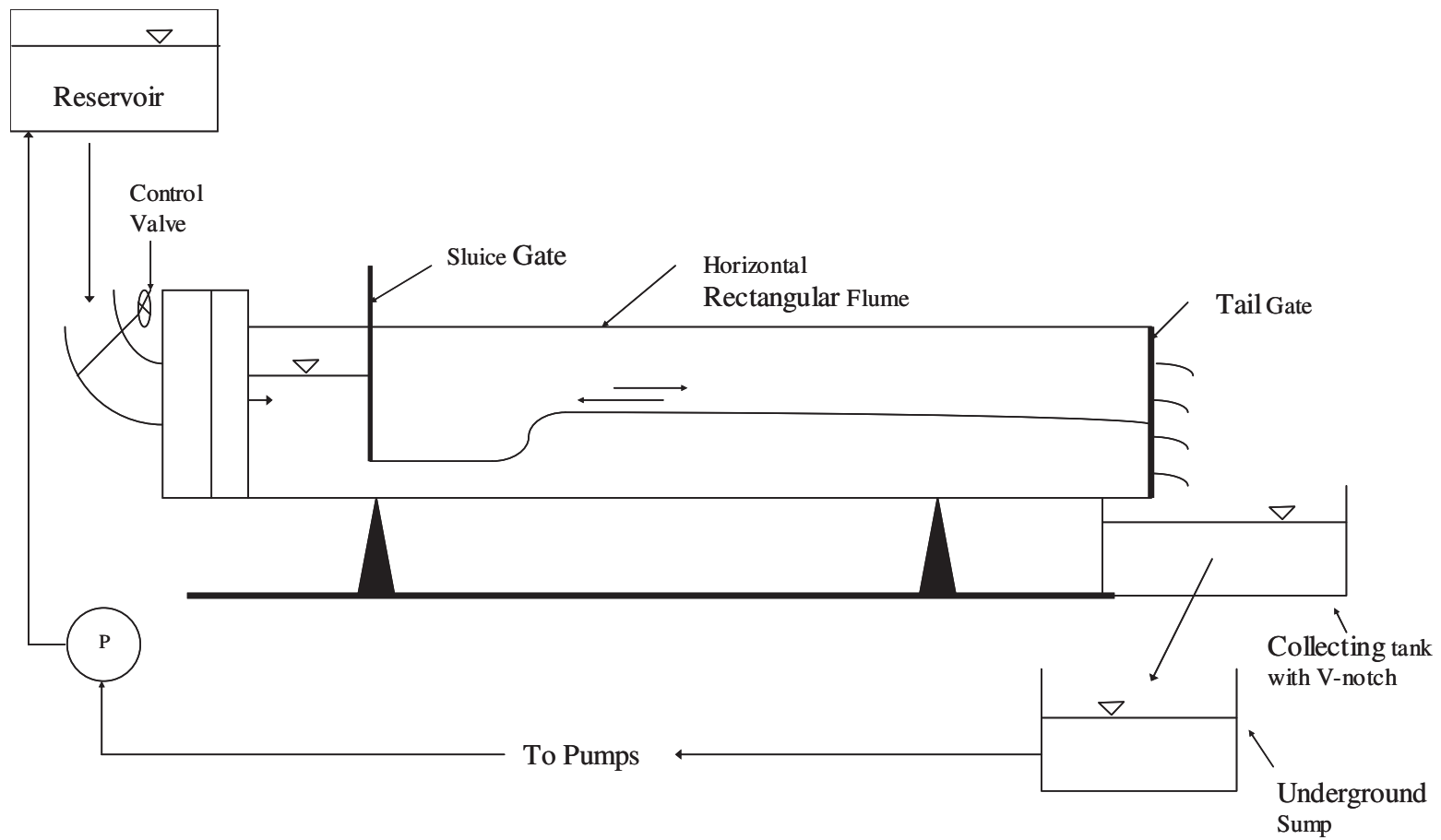

Figure 1: Experimental set-up

During the first stage of the study stationary hydraulic jumps were generated in the flume by adjusting the opening sizes of the sluice gate to $30 \mathrm{~mm}, 40 \mathrm{~mm}$ and $50 \mathrm{~mm}$ while keeping the same tail gate level. For each gate opening size, the water depth upstream of the sluice gate was increased in $10 \mathrm{~mm}$ steps by increasing the flow rate in the channel from $8 \mathrm{l} / \mathrm{s}$ to $26 \mathrm{l} / \mathrm{s}$ using the control valve. Once the steady state analysis was completed, the moving hydraulic jump was formed for the same flow range by changing the control valve gradually. This moving jump was recorded by two video cameras. Then the required data such as, water level upstream of the sluice gate and super critical and sub critical depths, position of the jump, length of the jump and the time taken to reach the corresponding upstream depth were recorded by digitizing the recorded video.

\subsection{Results}

\subsection{Stationary Hydraulic Jump}

The flow parameters such as discharge (Q), supercritical depth $\left(\mathrm{Y}_{1 \mathrm{~s}}\right)$, subcritical depth $\left(\mathrm{Y}_{2 \mathrm{~s}}\right)$, position of the jump toe $\left(X_{j s}\right)$ from the sluice gate, supercritical and subcritical flow velocities were recorded for each $10 \mathrm{~mm}$ increment in upstream water depth (Y3). The schematic diagram of the sluice gate is shown in Figure 2. The momentum equation is applied to stationary jump to derive a functional relationship for bed friction $(\mathrm{F})$ :

$\frac{1}{2} \gamma Y_{1 s}^{2}-\frac{1}{2} \gamma Y_{2 s}^{2}-F=\rho q\left(V_{2 s}-V_{1 s}\right) \ldots$.

Using the continuity equation;

$q=V_{1} Y_{1}=V_{2} Y_{2} ; V_{2}=\frac{V_{1} Y_{1}}{Y_{2}}$

Combining Eqns.(1) and (2),

$F=\frac{\rho g\left(Y_{1 s}^{2}-Y_{2 s}^{2}\right)}{2}-\frac{\rho q}{b}\left(V_{2 s}-V_{1 s}\right)$

where, subscript 1 denotes supercritical section and 2 denotes subcritical section, subscript $\mathbf{s}$ denotes stationary hydraulic jump condition, YFlow depth, V-velocity of the flow, $\rho$-density of water, $Q$ - flow rate and $\mathrm{F}_{\mathrm{r}}$ - Froude number. The variation of bed friction $(\mathrm{F})$ with flow rate $(\mathrm{Q})$ and flow rate $(\mathrm{Q}) \mathrm{Vs}$ position of the jump toe $\left(X_{\mathrm{js}}\right)$ are shown in Figures 3 and 4, respectively. 


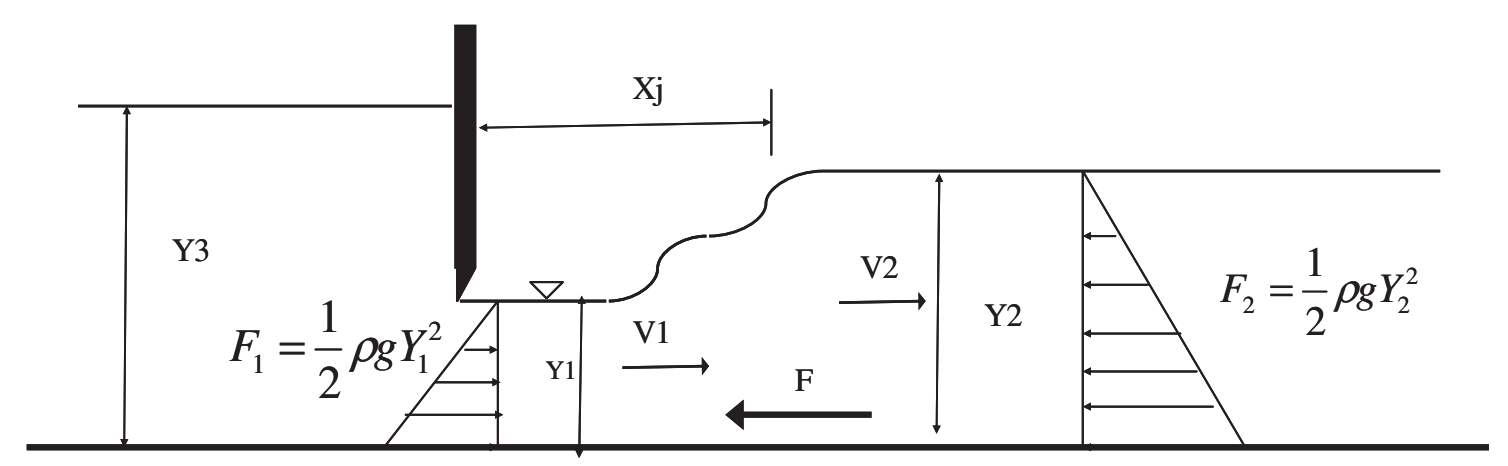

Figure 2: The schematic diagram of sluice gate and hydraulic jump

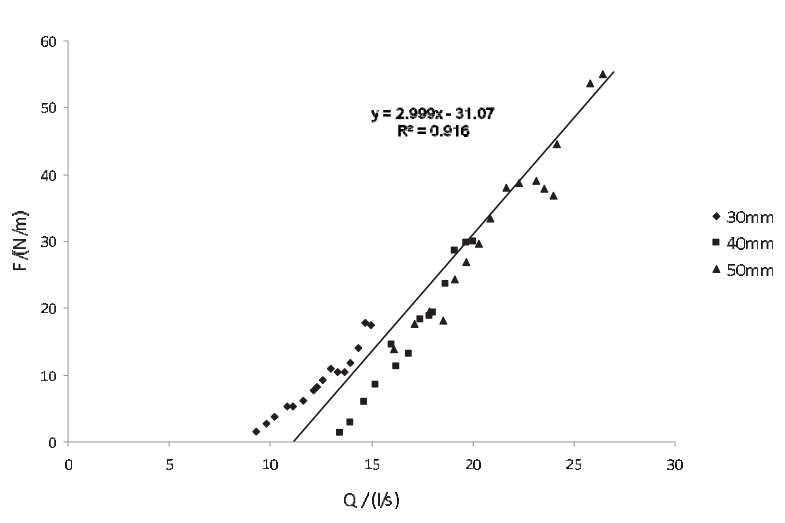

Figure 3: The variation of bed friction $(F)$ with flow rate $(Q)$

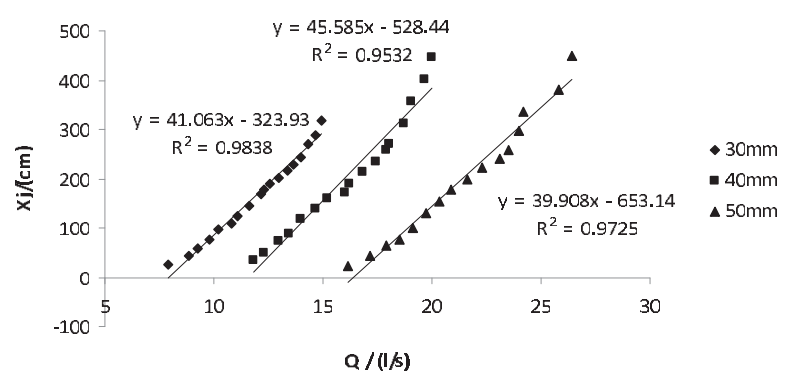

Figure 4: Position of the hydraulic jump $\left(X_{j}\right)$ Vs Flow rate $(Q)$

\subsection{Moving Hydraulic Jump}

Three different hydrographs were plotted for each opening size (30 mm, $40 \mathrm{~mm}$ and $50 \mathrm{~mm}$ ) at the upstream sluice gate. Figure 5 shows the recorded flow hydrographs.

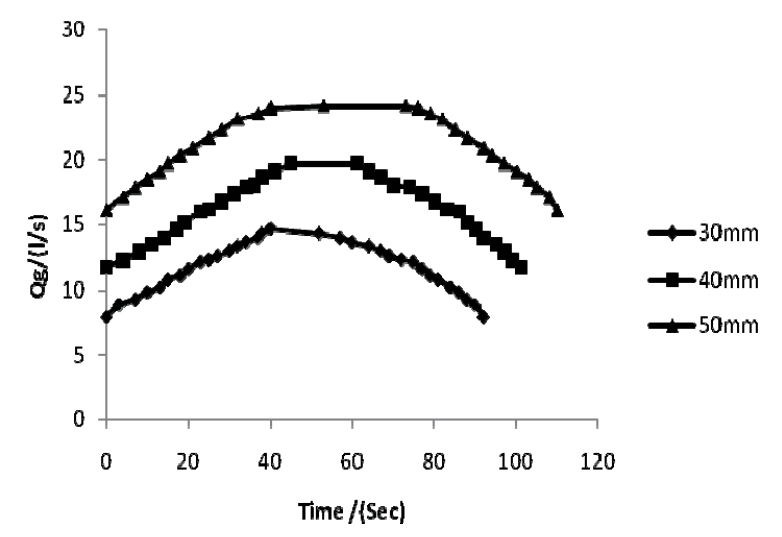

Figure 5: Recorded flow hydrographs for different gate openings

In order to present the results, moving hydraulic jump variables are listed as follows; supercritical depth $\left(\mathrm{Y}_{1 \mathrm{u}}\right)$, subcritical depth $\left(\mathrm{Y}_{2 \mathrm{u}}\right)$, specific energy at the downstream section $\left(E_{2 u}\right)$, flow rate at the gate $\left(\mathrm{Q}_{\mathrm{g}}\right)$, flow rate at the downstream section $\left(\mathrm{Q}_{2 \mathrm{u}}\right)$, pressure force at the downstream section $\left(\mathrm{F}_{\mathrm{p} 2 \mathrm{u}}\right)$ and density of water ( $\rho)$. The subscripts $\mathbf{1}$ and $\mathbf{2}$ indicate the variables associated with supercritical flow upstream and subcritical flow downstream of the moving jump while, subscripts $s$ and $\boldsymbol{u}$ denotes the stationary and unsteady flow conditions, respectively. The relationship between $E_{2 u}$ and $\mathrm{E}_{2 \mathrm{~s}}$ can be obtained using the energy equation as follows; 


$$
E_{2 s}-E_{2 u}=Y_{2 s}-Y_{2 u}+\frac{1}{2 g}\left(V_{2 s}^{2}-V_{2 u}^{2}\right) \ldots
$$

Then the task is to find out an empirical formula to estimate the flow rate at the downstream section $\left(\mathrm{Q}_{2 \mathrm{u}}\right)$. For this purpose a graph is plotted for specific energy difference $\left(E_{2 u}-E_{2 s}\right)$ against depth difference $\left(Y_{2 u}-Y_{2 s}\right)$ as shown in Figure 6.

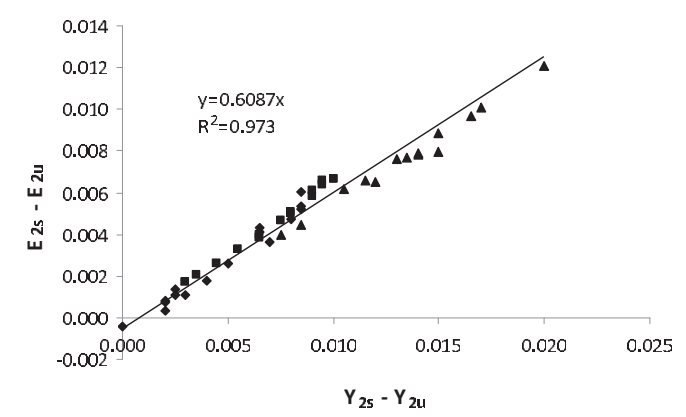

Figure 6: The variation between specific energy difference $\left(E_{2 s}-E_{2 u}\right)$ and depth difference $\left(\mathrm{Y}_{2 \mathrm{~s}}-\mathrm{Y}_{2 \mathrm{U}}\right)$

From the above graph the following relationship was obtained;

- $40 \mathrm{rm}$

$\triangle 50 \mathrm{~mm}$

$E_{2 s}-E_{2 u}=0.608\left(Y_{2 s}-Y_{2 u}\right)$

Then, substituting the terms for Eq. (3.5) from Eq. (3.4) gives;

$$
Y_{2 s}-Y_{2 u}+\frac{1}{2 g}\left(V_{2 s}^{2}-V_{2 u}^{2}\right)=0.608\left(Y_{2 s}-Y_{2 u}\right)
$$$$
Q_{2 u}=\sqrt{\frac{Q_{g}^{2}}{Y_{2 s}^{2}}-7.691 b^{2}\left(Y_{2 s}-Y_{2 u}\right)}
$$

Using the above equation $Q_{2 u}$ values for different opening sizes were calculated. Once $\mathrm{Q}_{2 \mathrm{u}}$ was obtained the relationship between moving hydraulic jump parameters were obtained. The variations are shown in Figure 7.

Then applying the momentum equations for the control volume;

$$
\begin{aligned}
& F_{p 1 u}-F_{p 2 u}-F=\frac{\rho}{b^{2}}\left(\frac{Q_{2 u}^{2}}{Y_{2 u}}-\frac{Q_{g}^{2}}{Y_{1 u}}\right) \ldots \ldots \ldots(7) \\
& F_{p 2 u}=\frac{\rho g Y_{1 u}^{2}}{2}-F-\frac{\rho}{b^{2}}\left(\frac{Q_{2 u}^{2}}{V_{2 u}}-\frac{Q_{g}^{2}}{Y_{1 u}}\right) \ldots \ldots(8)
\end{aligned}
$$

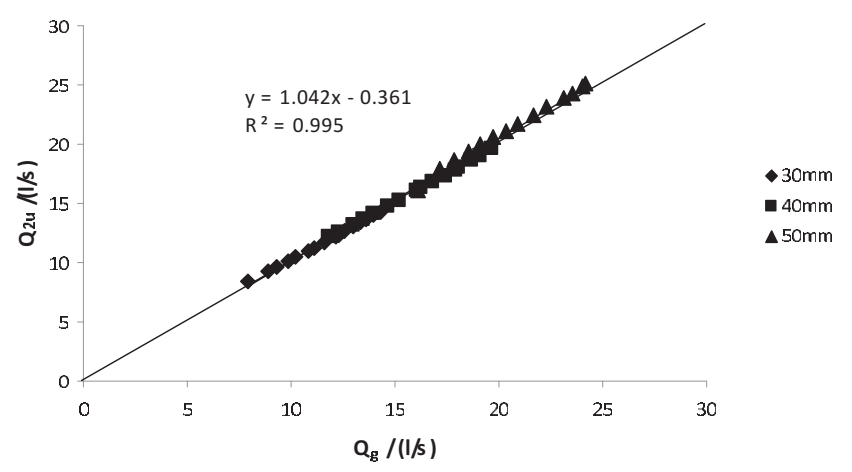

(a)

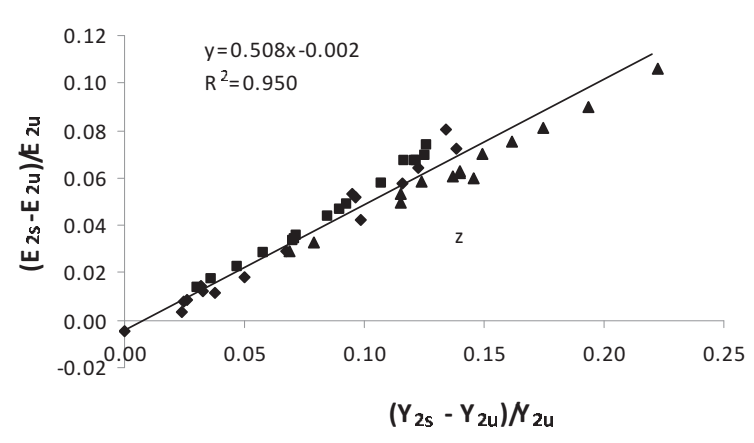

(b)

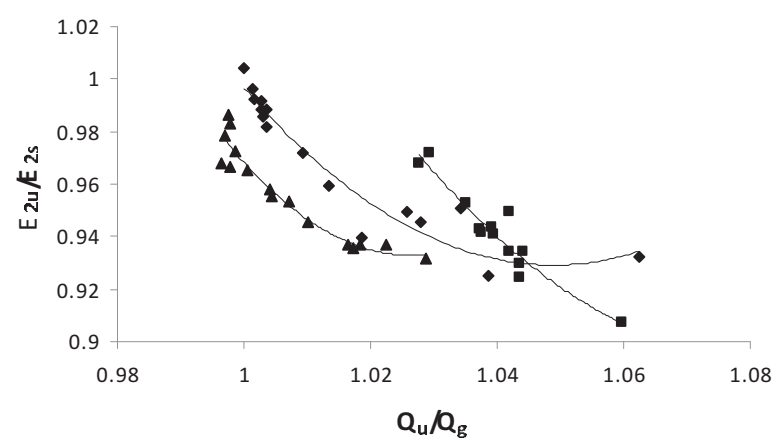

(c) 


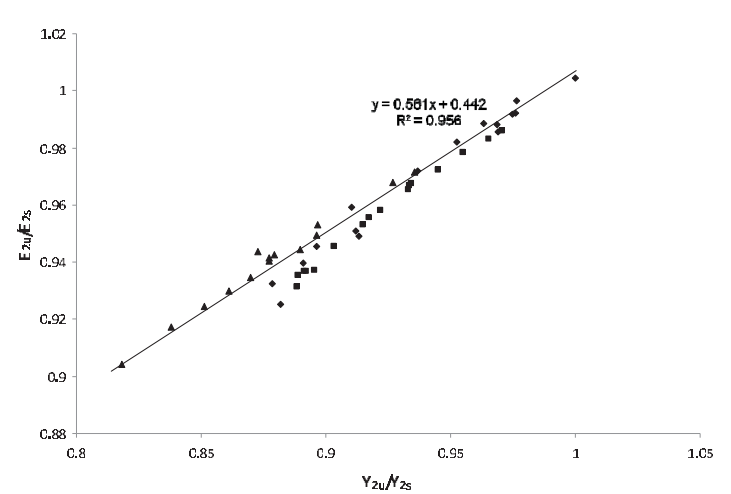

(d)

Figure 7: (a) Flow rate at the downstream section $\left(Q_{2 u}\right)$ against Flow rate at gate $\left(Q_{g}\right)(b)$ relative specific energy difference $\left\{\left(E_{2 s}-E_{2 u}\right)\right.$ / $\left.E_{2 u}\right\}$ against relative depth difference $\left\{\left(Y_{2 s}-\right.\right.$ $\left.\left.\mathrm{Y}_{2 \mathrm{U}}\right) / \mathrm{Y}_{2 \mathrm{u}}\right)$ (c) Specific energy ratio $\left(\mathrm{E}_{2 \mathrm{u}} / \mathrm{E}_{2 \mathrm{~s}}\right)$ against flow rate ratio $\left(Q_{\mathrm{u}} / \mathrm{Q}_{\mathrm{g}}\right)$ (d) specific energy ratio $\left(E_{2 u} / E_{2 s}\right)$ against depth ratio $\left(\mathrm{Y}_{2 \mathrm{u}} / \mathrm{Y}_{2 \mathrm{~s}}\right)$.

Then $\mathrm{F}_{\mathrm{p} 2 \mathrm{u}}$ was plotted against $\mathrm{Q}_{\mathrm{g}}$ for each opening size, as shown in Figure 8.

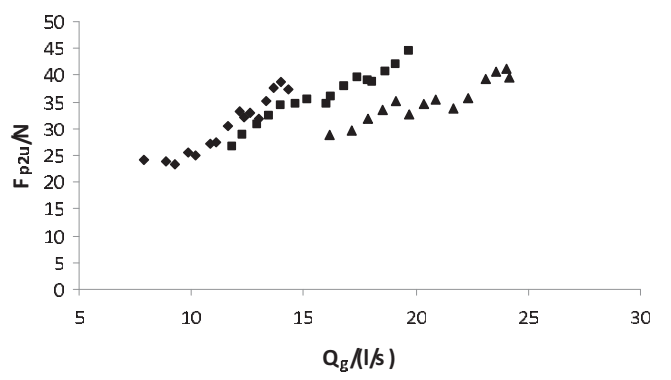

Figure 8: The variation between pressure forces at the downstream $\left(\mathrm{F}_{\mathrm{p} 2 \mathrm{u}}\right)$ and Flow rate at gate $\left(Q_{g}\right)$

\subsection{Discussion}

Bed Friction (F) linearly varies with the flow rate $(\mathrm{Q})$.Flow rate at downstream section $\left(\mathrm{Q}_{2 \mathrm{u}}\right)$ has a linear variation with the flow rate at gate $\left(\mathrm{Q}_{\mathrm{g}}\right) \cdot \mathrm{Q}_{2 \mathrm{u}}$ is approximately equal to $\mathrm{Q}_{\mathrm{g}}$ for smaller flow rates whereas it varies linearly for higher flow rates (see Figure 7 (a)).

$\mathrm{Q}_{2 \mathrm{u}}$ is the most dominant factor which affects all the other jump parameters of a moving hydraulic jump. Relative specific energy difference $\left\{\left(E_{2 s}-E_{2 u}\right) / E_{2 u}\right\}$ is proportional to relative depth difference $\left\{\left(\mathrm{Y}_{2 \mathrm{~s}}-\mathrm{Y}_{2 \mathrm{U}}\right) / \mathrm{Y}_{2 \mathrm{u}}\right\}$ for all the flow rates (see Figure 7 (b)). Since the downstream flow rate for moving jump is different from that of the stationary jump for the same upstream flow depth there is a specific energy difference. That difference is related to the difference in subcritical water depths. Specific energy ratio $\left(E_{2 u} / E_{2 s}\right)$ decreases with flow rate ratio $\left(Q_{u} / Q_{g}\right)$ for each opening sizes (see Figure 7 (c)).

Pressure force at the downstream section $\left(\mathrm{F}_{\mathrm{p} 2 \mathrm{u}}\right)$ increases with flow rate $\left(Q_{2 u}\right)$ for all the flow rates. Specific energy ratio $\left(E_{2 u} / E_{2 s}\right)$ has a linear variation with depth ratio $\left(\mathrm{Y}_{2 \mathrm{u}} / \mathrm{Y}_{2 \mathrm{~s}}\right)$ for all the flow rates (see Figure $7(d)$ ). This result can easily be interpreted if the derivation of Energy Equation is considered, because specific energy of a moving hydraulic jump is depending on $Y_{2 u}$ and $V_{2 u}$. There is a small difference between the values of $Y_{2 u}$ and $Y_{2 s}, V_{2 u}$ and $V_{2 s}$. This small variation may cause the linear variation.

The formula derived for flow rate $\left(\mathrm{Q}_{2 \mathrm{u}}\right)$ in the downstream of moving hydraulic jump is;

$Q_{2 u}=\sqrt{\frac{Q_{g}^{2}}{Y_{2 s}^{2}}-7.691 b^{2}\left(Y_{2 s}-Y_{2 u}\right)}$

The follwing formula was obtained for downstream pressure force of moving hydraulic jump;

$$
F_{p 2 u}=\frac{\rho g Y_{1 u}^{2}}{2}-F-\frac{\rho}{b^{2}}\left(\frac{Q_{2 u}^{2}}{V_{2 u}}-\frac{Q_{g}^{2}}{Y_{1 u}}\right) \ldots \ldots
$$

\subsection{Conclusions and Recommendation}

A series of experiments were conducted in a laboratory open channel to derive the relationship among moving hydraulic jump parameters. The correlation between stationary and moving hydraulic jump parameters were obtained in a non-dimensional form incorporating the bed friction of the flume.

There were some linear relationships between jump parameters which was independent of the gate opening size. Some of the relationships were non-linear and those were depending on 
the gate opening size. Bed friction varies linearly with the flow rate. There is a difference in pressure across the jump front which changes from hydrostatic value at the gate to a value higher than that at the downstream. It was observed that pressure force at downstream depends on flow rate at the gate, downstream flow rate, bed friction, super critical depth and subcritical depth for a moving hydraulic jump. An empirical formula for the flow rate at downstream for moving hydraulic jump was obtained using theoretical expressions and experimental results.

It was also observed that the flow rate at the downstream section is equal to the flow rate at the gate for smaller discharges whereas downstream flow rate is higher than the flow rate at the gate for higher flow rates. Also it was found that Specific Energy for stationary jump $\left(E_{2 s}\right)$ was greater than the energy for moving jump $\left(E_{2 u}\right)$ and this reduction is due to higher losses in moving hydraulic jump. This higher loss indicates the presence of turbulence.

Laboratory experiments covering a wide range of discharges are recommended to verify the results obtained during this study. Since most of the open channels in the field applications are trapezoidal in shape, this study could be extended for open channels having trapezoidal cross sections to investigate the dynamic behaviour of hydraulic jumps in these channels that could be very useful in field applications. In addition, the experiments with different boundary roughness and channel slopes are also needed for a complete study.

\section{References}

1. Araz M. Charangic and M. Hanif Chaudhry, "Numerical Simulation of Hydraulic Jump", ASCE, Journal of Hydraulic Eng., Vol-117, pp (1195-1211), 1991.

2. Hubert Chanson, "Dynamic Similarity and Scale Effects Affecting Air Bubble Entrainment in Hydraulic Jumps", 6th International Conference on Multiphase Flow, Germany, July, ICMF, pp (1-11), 2007.

3. Iwao Ohtsu, Youichi Yasuda, "Hydraulic Jump in Sloping Channels", ASCE, Journal of hydraulic Eng., Vol-117, pp (905-921), 1991.

4. Joel W. Toso, and C. Edward Bowers, ASCE, "Extreme Pressure in Hydraulic Jump-Stilling Basins", ASCE, Vol 114, pp (829-843), 1988.
5. Jung-fu yen, Chih-Han Llin and Chang-Tai Tsai, "Hydraulic Characteristics and Discharge Control of Sluice Gates" Journal of the Chinese Institute of Engineers, Vol -24, no 3, pp (301310), 2001.

6. Kim.W. and K.Y. Han. "Computation of Transcritical Flow by Implicit ENO Scheme", $4^{\text {th }}$ International Conference on Hydro-science and Engineering, September, pp (26-29), 2000.

7. Montes J.S. and H. Chanson, "Characteristics of Undular Hydraulic Jump Expreriments and Analysis", ASCE, Journal of Hydraulic Eng, Vol-124, pp (192-205), 1998.

8. Nalluri.C. \& R.E. Featherstone, Balckwell Publishing, Fourth Edition, "Civil Engineering Hydraulics", pp (204-209), 2001

9. Richard H. French, Mcgraw-Hill, International Edition, "Open Channel Hydraulics", pp (79102), 1986.

10. Rizi Parvaresh A., S. Kouchakzadeh and M.H. Omid, "A Study of Moving Hydraulic Jump in Rectangular Channels", Journal of Applied Science 6 (5), pp (1192-1198), 2006.

11. Tseng, M.H., C.A. Hsu and C.R Chu, "Channel Routing in Open-Channel Flow with Surges", ASCE, Journal of Hydraulic Eng., Vol-127, pp (115-122), 2001. 